\title{
Cdc42 controls progenitor cell differentiation and $\beta$-catenin turnover in skin
}

\author{
Xunwei Wu, ${ }^{1,6}$ Fabio Quondamatteo ${ }^{2}$ Tine Lefever, ${ }^{1,6}$ Aleksandra Czuchra, ${ }^{1}$ Hannelore Meyer, ${ }^{1}$ \\ Anna Chrostek, ${ }^{1}$ Ralf Paus, ${ }^{3,4}$ Lutz Langbein, ${ }^{5}$ and Cord Brakebusch ${ }^{1,6,7}$ \\ ${ }^{1}$ Max Planck Institute of Biochemistry, Heisenberg Group "Regulation of Cytoskeletal Organization," Department of \\ Molecular Medicine, 82152 Martinsried, Germany; ${ }^{2}$ Georg August University Göttingen, Department of Histology, 37075 \\ Göttingen, Germany; ${ }^{3}$ Max Planck Institute of Biochemistry, Department of Molecular Medicine, 82152 Martinsried, \\ Germany; ${ }^{4}$ University Hospital Schleswig-Holstein, Department of Dermatology, University of Lübeck, 23538 Lübeck, \\ Germany; ${ }^{5}$ Cell German Cancer Research Center, Department of Cell Biology, 69120 Heidelberg, Germany
}

Differentiation of skin stem cells into hair follicles (HFs) requires the inhibition of $\beta$-catenin degradation, which is controlled by a complex containing axin and the protein kinase GSK3ß. Using conditional gene targeting in mice, we show now that the small GTPase Cdc42 is crucial for differentiation of skin progenitor cells into HF lineage and that it regulates the turnover of $\beta$-catenin. In the absence of Cdc42, degradation of $\beta$-catenin was increased corresponding to a decreased phosphorylation of GSK3 $\beta$ at Ser 9 and an increased phosphorylation of axin, which is known to be required for binding of $\beta$-catenin to the degradation machinery. Cdc42-mediated regulation of $\beta$-catenin turnover was completely dependent on PKC $\zeta$, which associated with Cdc42, Par6, and Par3. These data suggest that Cdc42 regulation of $\beta$-catenin turnover is important for terminal differentiation of HF progenitor cells in vivo.

[Keywords: Rho GTPases; $\beta$-catenin; keratinocytes]

Supplemental material is available at http://www.genesdev.org.

Received August 2, 2005; revised version accepted January 12, 2006.

Cdc42 is a ubiquitously expressed small GTPase belonging to the Rho family (Etienne-Manneville and Hall 2002). It exists in an active GTP-bound and an inactive GDP-bound form. Signaling by integrins, growth factor and cytokine receptors, and cadherins can activate Cdc42 by stimulating the exchange of GDP to GTP, catalyzed by guanine-nucleotide exchange factors (GEFs). Only in its active form can Cdc42 interact with different effector molecules such as PAK1-4, N-WASP, IQGAP, and Par6, which in turn regulate the actin cytoskeleton, microtubule network, cell polarity, proliferation, apoptosis, endocytosis, and secretion (Bishop and Hall 2000). Since many of these effectors are expressed tissue specifically in different amounts, the consequences of Cdc42 activation are dependent on the cell type. Mice with a constitutive knockout of $\mathrm{Cdc} 42$ die around implantation, indicating the importance of Cdc42 function in vivo (Chen et al. 2000), but preventing the analysis of Cdc42 at later time points of development.

\footnotetext{
${ }^{6}$ Present address: Group of Developmental Biology, Institute of Molecular Pathology, Copenhagen University, 2100 Cophenhagen, Denmark. ${ }^{7}$ Corresponding author.

E-MAIL cord@pai.ku.dk; FAX 45-353-26081.

Article and publication are at http://www.genesdev.org/cgi/doi/10.1101/ gad.361406.
}

Currently, nothing is known about the role of Cdc42 in skin development and maintenance. Although Cdc42 was shown to regulate many cellular processes, a crucial role for Cdc42 in differentiation has not been demonstrated so far.

The skin is made of epidermis /consisting primarily of keratinocytes) and an underlying dermis, separated by a basement membrane (BM) (Alonso and Fuchs 2003). Attached to the BM are the basal keratinocytes. To further differentiate they detach from the BM, stop proliferation, and become suprabasal keratinocytes. Finally, these cells undergo an apoptosis-related process called "terminal differentiation" and form the stratum corneum, which seals the skin to the outside (Gandarillas 2000). Keratinocyte stem cells also give rise to skin appendages such as sebaceous glands and hair follicles (HFs). During embryogenesis, HF morphogenesis is initiated by a crosstalk between epithelial keratinocytes and mesenchymal cells (Schmidt-Ullrich and Paus 2005). Wnt signaling and stabilization of $\beta$-catenin is required for formation of the hair placode, but also for the differentiation of progenitor cells into companion, inner root sheath (IRS), and hair shaft (HS) layers. If $\beta$-catenin is lost after HF morphogenesis, follicle progenitor cells change their fate decision from HF to epidermal differentiation (Huelsken et 
al. 2001). Cytosolic levels of $\beta$-catenin are tightly regulated by a complex containing APC, axin, and GSK3 $\beta$, which binds and phosphorylates $\beta$-catenin, thus targeting it for proteasomal degradation. $\beta$-catenin is phosphorylated by GSK3 $\beta$, which also phosphorylates axin (Willert et al. 1999). Only if axin is phosporylated can $\beta$-catenin bind efficiently to the degradation complex. Wnt signaling inhibits the kinase activity of GSK3 $\beta$ in this complex, leading to stabilization of $\beta$-catenin that can then move to the nucleus, where it associates with transcription factors of the LEF/TCF family and induces the expression of HF-specific genes (Alonso and Fuchs 2003). Many data suggested that GSK3 $\beta$ in the Wnt pathway is insulated from regulators of GSK3 $\beta$ that lie outside of the Wnt pathway. For example, insulin-induced phosphorylation of GSK3 $\beta$ at Ser 9, which inhibits the kinase activity of GSK3 $\beta$, does not affect degradation of $\beta$-catenin (Ding et al. 2000; Yuan et al. 1999). Recently, however, LKB1/XEEK1 was suggested to affect Wnt signaling by $\mathrm{PKC} \zeta$-mediated phosphorylation of GSK3 $\beta$ (Ossipova et al. 2003). Furthermore, Cdc42 was described to regulate $\beta$-catenin turnover in cultured astrocytes via Par6-PKC $\zeta$-mediated phosphorylation of GSK3 $\beta$ (Etienne-Manneville and Hall 2003).

To analyze the function of Cdc42 in skin and to test whether Cdc42 is important in skin progenitor cell differentiation, we generated mice with a keratinocyte-restricted deletion of the Cdc42 gene. We show now that Cdc42 is crucial for the fate decision of epidermal progenitor cells in the HF and that it regulates $\beta$-catenin degradation in vivo and in vitro. In addition, our data indicate that $\mathrm{Cdc} 42$ is important for cell-cell contacts between keratinocytes at least partially by controlling the degradation of $\beta$-catenin and plakoglobin.

\section{Results}

Progenitor fate decision in the HF is defective in the absence of $\mathrm{Cdc} 42$

Using the cre-loxP system mice with a keratinocyte-restricted deletion of the Cdc42 gene were generated (Fig. 1A; Supplementary Fig. 9A). Mutant offspring (Cdc $42^{\mathrm{fl} / \mathrm{fl}}$ K5) showed an efficient loss of Cdc42 protein in primary keratinocytes and epidermal lysates isolated from embryonic day 18.5 (E18.5), 3-mo-old, and 4-mo-old mice (Fig. 1B). Littermates heterozygous for the conditional Cdc42 gene and expressing the cre recombinase $\left(\mathrm{Cdc} 42^{\mathrm{fl} /+} \mathrm{K} 5\right)$, which were used as controls, expressed still high amounts of Cdc42. Mutant mice were born without obvious defects, but showed impaired hair formation and growth retardation of $\sim 30 \%$ in 2 -wk-old animals (Fig. 1C). Within $4 \mathrm{wk}$, all hairs were lost and did not grow again in older mice (Fig. 1C).

Although Cdc42 mutant mice showed highly impaired hair coat development, the density of HFs in the back skin of 3-d-old mutant mice was not significantly altered (Fig. 1D; control [con]: $3.8 \pm 0.3 \mathrm{HFs} /$ micron of epidermis; $\mathrm{Cdc} 42^{\mathrm{fl} / \mathrm{fl}} \mathrm{K} 5$ cre [ko]: $3.6 \pm 0.2 \mathrm{HFs} /$ micron of epidermis; $n=3,>100$ HFs counted/mouse), as assessed by hematoxylin-eosin staining. The average length of the HFs, however, was significantly reduced (con: $253.4 \pm 20.7 \mu \mathrm{m}$; ko: $107.9 \pm 19.6 \mu \mathrm{m} ; n=3,>100 \mathrm{HFs}$ measured/mouse; $p<0.005$ ). This documents a severe delay in postnatal HF morphogenesis. In HFs of 2-wk-old control mice, hair matrix, IRS, and HS cells were readily distinguishable (Fig. 1D, hair matrix [blue arrowheads], IRS [arrows], HS [black arrowheads]). In mutant animals no typical hair matrix, IRS, or HS cells were observed. Large, roundish cells with weak nuclear staining, similar to suprabasal cells of the epidermis, were found in place of hair matrix (Fig. 1D, blue arrows) or IRS cells (Fig. 1D, white arrows). Furthermore, stratum corneum extended deep into the HFs of mutant mice (Fig. 1D, white arrowheads).

While in 3-d-old mice the number of proliferating $\mathrm{Ki} 67^{+}$cells was similar in the hair matrix of control and mutants, proliferation became reduced by postnatal day 9 (P9) (Supplementary Fig. 1A, $\mathrm{A}^{\prime}, \mathrm{B}, \mathrm{B}^{\prime}$ ). In 2-wk-old mutant mice proliferating $\left(\mathrm{BrdU}^{+}\right)$cells were found only in the outermost layer of the HF, whereas in controls most cells of the hair matrix were dividing (Supplementary Fig. $1 \mathrm{C}, \mathrm{C}^{\prime}$ ).

To investigate abnormalities in HF differentiation we then assessed the expression of HF-specific keratins, which are hardly detectable at $3 \mathrm{~d}$, but are strongly expressed in HFs of 9- and 14-d-old control mice. Mutant mice showed a progressive loss of specific IRS and HS markers. At 9 d, mutant mice displayed reduced levels of K6irs2 (IRS cuticle) (Supplementary Fig. 1D,D') and hHa5 (HS matrix) (Supplementary Fig. 1E,E'), while at 14 $\mathrm{d}$ of age no staining could be detected for any HF-specific keratin tested (K6irs1 [all IRS], K6irs3 [IRS cuticle], hHb2 [HS cuticle], hHa4 [upper cortex of HS]) (Fig. 2A'-D') in contrast to control mice (Fig. 2A-D). Instead, mutant HFs expressed $\mathrm{K} 10$ and loricrin (Fig. 2E', $\mathrm{F}^{\prime}$, arrows), which are normally not found in HFs, but are a characteristic of epidermis (Fig. 2E,F).

Expression and localization of the adherens junction proteins E-cadherin and $\alpha$-catenin and of the tight junction markers ZO-1 and occludin were similar in HFs of 3 - and 9-d-old control and mutant mice (Supplementary Fig. 3A-D,F-K, $\left.\mathrm{A}^{\prime}-\mathrm{D}^{\prime}, \mathrm{F}^{\prime}-\mathrm{K}^{\prime}\right)$. At $14 \mathrm{~d}$, E-cadherin and $\alpha$-catenin were still present in Cdc42-null HFs, while ZO-1 and occludin were strongly reduced (Fig. 2G, G', arrows; Supplementary Fig. $3 \mathrm{M}-\mathrm{P}, \mathrm{M}^{\prime}-\mathrm{P}^{\prime}$, arrows). Also the thick actin bundles characteristic for ORS cells were lost in the absence of Cdc42 (Fig. $\left.2 \mathrm{H}_{,} \mathrm{H}^{\prime}\right)$. Staining for the Cdc42 effector IQGAP1 was similar in HFs of 3-d-old control and mutant mice (Supplementary Fig. 3E, $E^{\prime}$ ), while at $9 \mathrm{~d}$ Cdc42-null HFs displayed reduced amounts of IQGAP1 in the ORS layer (Supplementary Fig. 3L, L').

Versican expression of fibroblasts in the dermal papilla correlates with their ability to induce hair growth in the skin of nude mice (Kishimoto et al. 2000). In contrast to control mice, versican-expressing dermal papillas were hardly detectable in HF of 2-wk-old mutant mice (Supplementary Fig. 2A, A', arrow). Since the knockout of Cdc42 was restricted to keratinocytes, this change in dermal papilla versican expression indicates defective epithelial-mesenchymal cross-talk. 
Downloaded from genesdev.cshlp.org on April 26, 2023 - Published by Cold Spring Harbor Laboratory Press

Cdc42 function in keratinocytes in vivo

$\mathbf{A}$
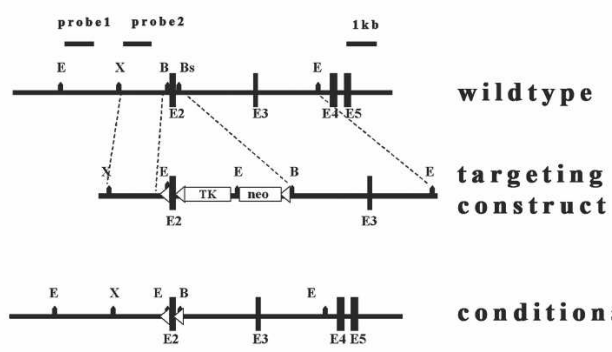

condition a 1

C

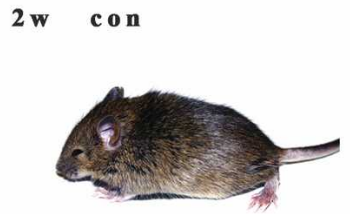

2 w ko

$4.5 \mathrm{mocon}$

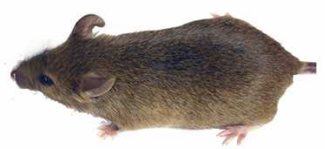

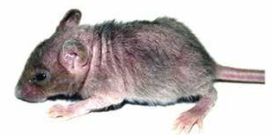

$4.5 \mathrm{mo} \mathrm{ko}$

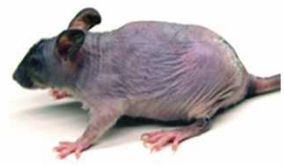

B

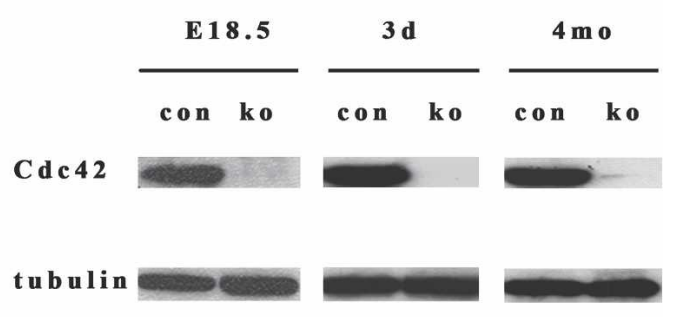

D
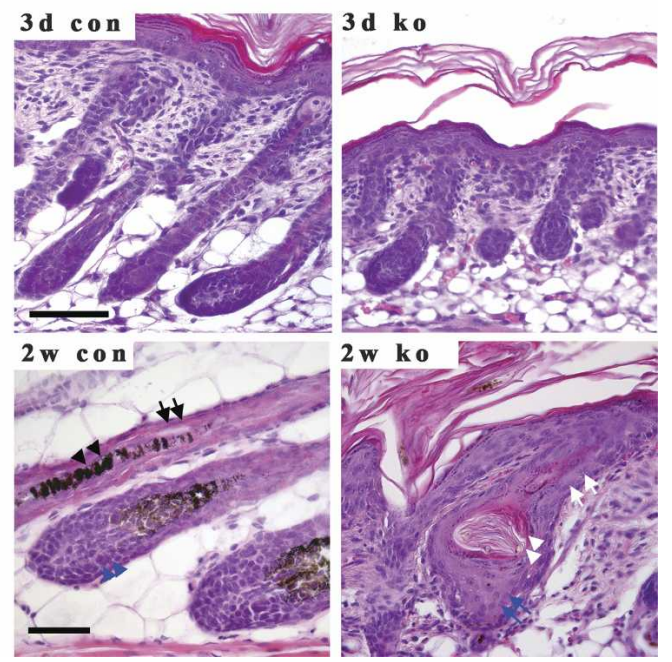

Figure 1. Generation of mice with a keratinocyte-restricted deletion of the Cdc42 gene. $(A)$ Targeting scheme showing the Cdc42 gene (wild type), the targeting construct, and the conditional allele after homologous recombination of the targeting construct and removal of the floxed neo-tk cassette by transient cre transfection. (Filled boxes) Exons; (tk) thymidin kinase expression cassette; (neo) neomycin resistance expression cassette; (triangles) loxP sites; (E) EcoRI; (X) XbaI; (B) BamHI; (Bs) BsrGI; (probe 1) external probe; (probe 2) internal probe. Both probes were used after EcoRI digestion. (B) Western blot analysis for Cdc42 and tubulin of epidermal lysates of E18.5, 3-d-old, and 4-mo-old mice of the indicated genotypes. (C) Photographs of 2-wk-old and 4.5-mo-old mice with a keratinocyterestricted deletion of the $\mathrm{Cdc} 42$ gene, together with corresponding control mice. Mutant mice showed progressive loss of hairs. $(D)$ Hematoxylin-eosin (HE)-stained paraffin sections of back skin of 3-d-old and 2-wk-old Cdc $42^{\mathrm{fl} / \mathrm{fl}} \mathrm{K} 5 \mathrm{cre}$ (ko) and control (con) mice. HFs of 3-d-old mutant mice were shorter than in controls. Two-week-old mutants showed an aberrant HF morphology lacking normal hair matrix (con: blue arrowheads; ko: blue arrows), IRS (con: black arrows; ko: white arrows), and HS (con: black arrowheads; ko: white arrowheads).

Absence of hair bulb cells containing the apoptotic marker cleaved caspase-3 in Cdc42-deficient mice at 3 and $9 \mathrm{~d}$ of age indicated that the loss of HF-specific gene expression is not due to a premature catagen initiation

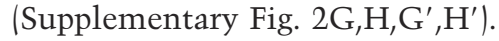

In 4.5-mo-old mutant mice, dermal cysts were detected (Fig. 2I). These cysts consisted of several layers of cells organized as the epidermis in basal layers $\left(\mathrm{K}_{14}{ }^{+}\right.$, $\mathrm{K}^{-}{ }^{-}$) (Fig. 2J; Supplementary Fig. 2B), suprabasal layers $\left(\mathrm{K}^{-} \mathrm{O}^{+}\right)$(Fig. 2J), and terminally differentiating cells (loricrin $^{+}$) (Supplementary Fig. 2C). Such cysts were never found in control mice. Intriguingly, such cysts have previously been detected in mice lacking functional $\beta$-catenin or LEF-1, a $\beta$-catenin-binding transcription factor, in keratinocytes (Huelsken et al. 2001; DasGupta et al. 2002; Niemann et al. 2002).
Taken together, these data show that in the absence of Cdc42 epithelial progenitor cells in the HF change their fate decision from HF keratinocytes to keratinocytes of the epidermis. Interestingly, sebaceous glands were still present in these mice (Fig. $2 \mathrm{~K}, \mathrm{~K}^{\prime}$, arrows), indicating that differentiation of skin stem cells into sebocytes was not impaired.

Transcription factors inducing HF-specific genes are lost

Normal hair morphogenesis requires $\beta$-catenin, which translocates from the cytoplasm to the nucleus where it associates with transcription factors of the LEF/TCF family to induce the expression of HF-specific genes (Schmidt-Ullrich and Paus 2005). Since the HF pheno- 

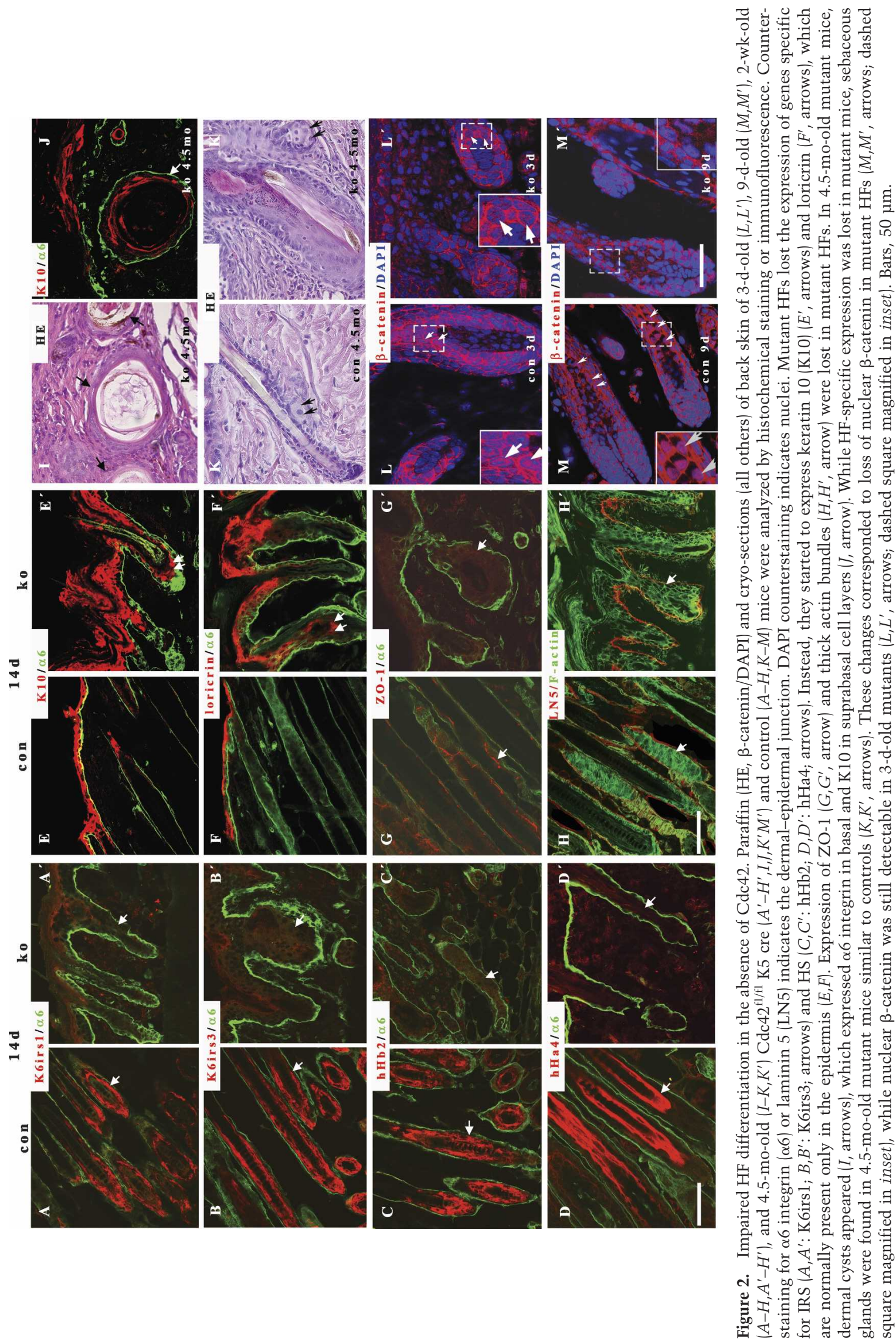
type of Cdc42-deficient mice has similarities to that of mice lacking $\beta$-catenin in keratinocytes-i.e., loss of HFspecific proteins, expression of epidermis markers, formation of dermal cysts, and maintenance of sebaceous glands (Huelsken et al. 2001)-we tested whether $\beta$-catenin is reduced in the HFs of Cdc42-mutant animals.

Immunofluorescence analysis detected nuclear $\beta$-catenin in the precortex region of mutant HFs at $3 \mathrm{~d}$ (Fig. $2 \mathrm{~L}, \mathrm{~L}^{\prime}$, arrows), but a loss of nuclear $\beta$-catenin at $9 \mathrm{~d}$ (Fig. $2 \mathrm{M}, \mathrm{M}^{\prime}$, arrows), while it was still present at the cellcell junctions. At 9 d, LEF-1 showed nuclear localization in the precortex region of both normal and mutant HFs (Supplementary Fig. 2D,D', arrows). However, in 2 -wk-old mutant mice, LEF-1 was not detectable any more, in contrast to control mice (Supplementary Fig. $2 \mathrm{E}, \mathrm{E}^{\prime}$, arrow).

These data suggest a specific reduction of nuclear $\beta$-catenin and subsequent decline in LEF-1 as a possible explanation for the loss of HF-type epithelial differentiation.

In the absence of Cdc42, basal keratinocytes show increased proliferation, but can terminally differentiate

Two-week-old mutant mice exhibited a strong hyperplasia and hyperkeratosis of the epidermis (Fig. 3A'). While in control mice K14 was mainly expressed by basal keratinocytes, K14 was clearly present in all epidermal cells of mutant mice (Fig. 3C, C'). Hyperplasia was likely caused by an enlarged suprabasal keratinocyte compartment as indicated by keratin 10 expression (Fig. 3D, $\mathrm{D}^{\prime}$ ). Terminal differentiation as indicated by the expression of loricrin was similar in mutant and control animals (Fig. 3E, E'). Keratin 6 is normally not expressed in the epidermis (Supplementary Fig. 2F), but can be up-regulated in hyperproliferative conditions. Mutant mice showed a strong expression of keratin 6 in the suprabasal layers of the epidermis (Supplementary Fig. $2 \mathrm{~F}^{\prime}$ ).

Counting of $\mathrm{BrdU}^{+}$cells in the interfollicular epidermis indicated a significantly increased proliferation in 2 -wk-old mutant mice restricted to basal keratinocytes (Fig. $3 \mathrm{~B}, \mathrm{~B}^{\prime}$ ): Whereas in normal skin $6.8 \pm 2.3 \%$ of the basal keratinocytes were $\mathrm{BrdU}^{+}$, this number increased to $14.2 \pm 5.6 \%$ in mutant mice $(n=3 ; p<0.05)$.

\section{Loss of cell-cell contacts in epidermis of old mice} lacking Cdc42 in keratinocytes

Keratinocytes adhere to each other via adherens junctions consisting of E-cadherin, $\beta$-catenin, and $\alpha$-catenin, which is attached to the actin cytoskeleton, or via desmosomes containing plakoglobin. In 2-wk-old Cdc42deficient mice, hematoxylin-eosin staining did not reveal defective cell-cell contacts (Fig. 3A, $\mathrm{A}^{\prime}$ ). Furthermore, staining for the junctional proteins E-cadherin, $\alpha$-catenin, $\beta$-catenin, ZO- 1 , and occludin at 3,9 , and 14 $\mathrm{d}$ did not indicate obvious disturbances of cell-cell junc-
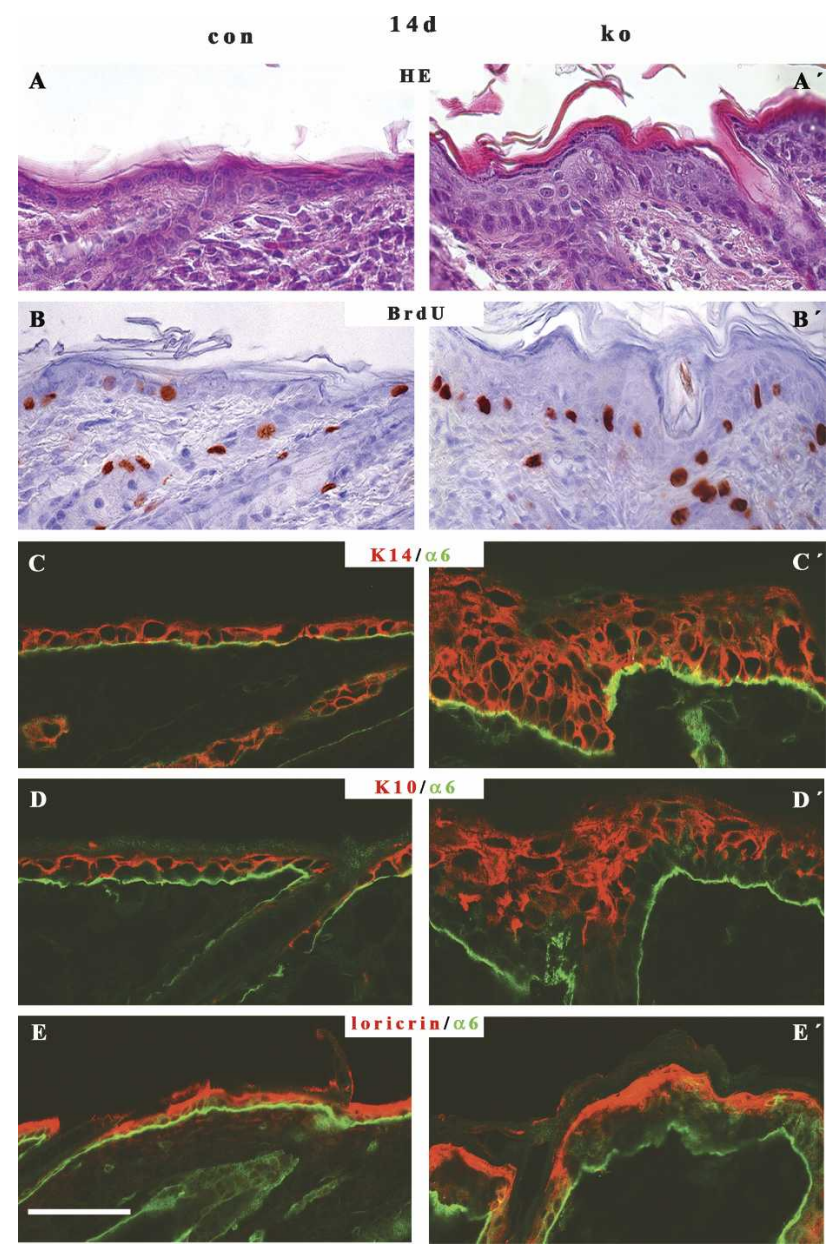

Figure 3. Epidermal hyperplasia in Cdc42-deficient skin. Paraffin (HE, BrdU) and cryo-sections (K14, K10, loricrin) of back skin of 14-d-old $\left(A-E, A^{\prime}-E^{\prime}\right) \mathrm{Cdc} 42^{\mathrm{fl} / \mathrm{fl}} \mathrm{K} 5$ cre $\left(\mathrm{ko}, A^{\prime}-E^{\prime}\right)$ and control mice (con, $A-E$ ) were analyzed by histochemical staining and immunofluorescence. Mutant mice showed epidermal hyperplasia in hematoxylin-eosin staining $\left(\mathrm{HE}_{;} A, A^{\prime}\right)$, corresponding to an increased proliferation of basal keratinocytes as detected by BrdU incorporation (BrdU; $\left.B, B^{\prime}\right)$. Cdc42-deficient keratinocytes developed from basal (K14: keratin $\left.14 ; C, C^{\prime}\right)$ to suprabasal (K10: keratin $\left.10 ; D, D^{\prime}\right)$ and terminally differentiating cells (loricrin; $\left.E, E^{\prime}\right)$. $\left(C-E, C^{\prime}-E^{\prime}\right)$ Counterstaining for $\alpha 6$ integrin $(\alpha 6)$ indicates the dermal-epidermal junction. Bar, $50 \mu \mathrm{m}$.

tions in mutant mice (Supplementary Fig. 4A-E, $\mathrm{A}^{\prime}-\mathrm{E}^{\prime}$, $\left.\mathrm{G}-\mathrm{K}, \mathrm{G}^{\prime}-\mathrm{K}^{\prime}, \mathrm{M}-\mathrm{Q}, \mathrm{M}^{\prime}-\mathrm{Q}^{\prime}\right)$.

Mice older than $4 \mathrm{mo}$, however, displayed significant widening of the intercellular space between keratinocytes in many areas of the epidermis (Supplementary Fig. 5A, $\mathrm{A}^{\prime}$ and enlarged in $\left.\mathrm{B}, \mathrm{B}^{\prime}\right)$. Even intraepidermal microblisters were frequently observed in mutant mice (Supplementary Fig. 5A', $\mathrm{B}^{\prime}$, arrows). These defects were found in most, but not in all, parts of the epidermis. Electron microscopical analysis demonstrated that mutant keratinocytes had long protrusions, some of them making contacts to neighboring keratinocytes (Supplementary Fig. 5C, C'). In 4.5-mo-old mutant mice, desmosomes were found without obvious morphological 
alterations that were unevenly distributed over the cell surface (Supplementary Fig. 5D,D'; data not shown), although the number of desmosomes in the basal keratinocyte layer was not significantly changed (con: $10 \pm 3.7$ desmosomes/medially sectioned basal keratinocyte; ko: $7 \pm 3.3$; 10 keratinocyctes counted; $p>0.05$ ).

To investigate the reason for this cell-cell adhesion defect, intracellular localization and expression of Ecadherin, plakoglobin, or $\alpha$-catenin in keratinocytes were examined, since loss of these molecules results in defective cell-cell contacts in vivo (Bierkamp et al. 1999; Vasioukhin et al. 2001; Young et al. 2003; Tinkle et al. 2004). Indeed, membranous localization of Ecadherin, plakoglobin, $\beta$-catenin, and $\alpha$-catenin was strongly decreased in 4.5-mo-old mice lacking Cdc42, most prominently in basal keratinocytes (Supplementary Fig. 5E-H, $\mathrm{E}^{\prime}-\mathrm{H}^{\prime}$ ). Western blot analysis of epidermal lysates of 4.5 -mo-old control and mutant mice confirmed the reduction of E-cadherin, plakoglobin, $\beta$-catenin, and $\alpha$-catenin protein in Cdc42-deficient epidermis (quantification in Supplementary Fig. $5 \mathrm{E}^{\prime \prime}-\mathrm{H}^{\prime \prime}$; representative blots in Supplementary Fig. 8A). In the absence of Cdc42, staining for F-actin was more diffuse in the basal keratinocyte layer, while it appeared to be similar to controls in suprabasal regions (Supplementary Fig. 5I, $\left.\mathrm{I}^{\prime}\right)$.

p120 catenin associates with E-cadherin and was proposed to regulate E-cadherin transport to the cell surface, its retention at the membrane, and lysosomal degradation (Peifer and Yap 2003). In the absence of Cdc42, p120 was still expressed normally as assessed by Western blotting (Supplementary Fig. 5J"), indicating that the reduction of E-cadherin is not caused by a reduction of p120. As expected, p120 localization at the cell membrane was reduced in basal keratinocytes (Supplementary Fig. 5J, J') due to the decreased membrane localization of E-cadherin (Thoreson et al. 2000).

Cdc42-GTP reportedly strengthens cell-cell adhesion by binding to IQGAP1 and preventing its interaction with $\beta$-catenin (Kuroda et al. 1998). Loss of Cdc42, therefore, was expected to result in an increased binding of IQGAP1 to junctional $\beta$-catenin and reduced cell-cell contacts. However, no obvious change in IQGAP1 was detected in the epidermis of 3- and 9-d-old mutant mice (Supplementary Fig. 4F, $\mathrm{F}^{\prime}, \mathrm{L}, \mathrm{L}^{\prime}$ ). In keratinocytes of 2-wkold mutant mice, membrane association of IQGAP1 appeared to be reduced, although junctional $\beta$-catenin was not visibly altered (Supplementary Fig. 4R, $\mathrm{R}^{\prime}, \mathrm{O}^{\prime} \mathrm{O}^{\prime}$ ). Also in 4.5-mo-old mutant mice, IQGAP1 showed reduced membrane localization (Supplementary Fig. $5 \mathrm{~K}, \mathrm{~K}^{\prime}$ ). In addition, IQGAP1 protein levels were decreased (Supplementary Fig. $5 \mathrm{~K}^{\prime \prime}$ ), suggesting a role of Cdc42 in IQGAP1 expression or turnover.

Loss of $\beta$-catenin precedes loss of E-cadherin in Cdc42-deficient epidermis

To understand the reason for the loss of E-cadherin, $\beta$-catenin, and plakoglobin in Cdc42-deficient keratinocytes of 4.5-mo-old mice, we analyzed the kinetics of these changes by Western blot analysis of epidermal lysates. While 2-wk-old mutant mice showed normal amounts of total cellular E-cadherin, $\beta$-catenin, and plakoglobin, 3-mo-old mutant mice exhibited a reduction of total cellular $\beta$-catenin, but no major changes in E-cadherin or plakoglobin levels (quantification in Fig. 4A; representative blots in Supplementary Fig. 8A). Only 4.5mo-old mice showed a reduction in the total cellular amounts of all three proteins in the absence of Cdc42. These data demonstrate that loss of $\beta$-catenin in Cdc42null keratinocytes is not caused by a reduction of E-cadherin, but that loss of $\beta$-catenin precedes the loss of $\mathrm{E}$ cadherin and plakoglobin.

Northern blot analysis of mRNA from epidermis of 2.5- and 3.5-mo-old mice revealed no changes in the amount of $\beta$-catenin message, suggesting that the reduction of $\beta$-catenin protein is most likely due to increased degradation of $\beta$-catenin (Supplementary Fig. 8B).

In vivo, phosphorylation of PKC $\zeta$ and GSK3 $\beta$ are reduced in the absence of $\mathrm{Cdc} 42$

In astrocytes, $\mathrm{Cdc} 42$ regulates the degradation of $\beta$-catenin by controlling the $\mathrm{PKC} \zeta$-mediated phosphorylation of GSK3 $\beta$ (Etienne-Manneville and Hall 2001, 2003). GSK3 $\beta$ is part of a complex that binds and phosphorylates free, cytosolic $\beta$-catenin, thus targeting it for degradation (Doble and Woodgett 2003). Phosphorylation of GSK3 $\beta$ at Ser 9 reduces GSK3 $\beta$-mediated phosphorylation of $\beta$-catenin and thus stabilizes $\beta$-catenin. If this pathway also operates in keratinocytes in vivo, one would expect a reduced phosphorylation of GSK3 $\beta$ at Ser 9 in the absence of Cdc42.

We tested this hypothesis by immunofluorescent staining of skin sections and Western blotting of epidermal lysates, using antibodies specifically recognizing phosphorylated and supposedly active PKC $\zeta(\mathrm{p}-\mathrm{PKC} \zeta)$ and GSK3 $\beta$ phosphorylated at Ser 9 (p-GSK3 $\beta$ ). In 3-, 9-, and 14-d-old control mice, p-PKC $\zeta$ and p-GSK3 $\beta$ were found in the matrix region of the hair bulb (Fig. 4D,F, arrows; Supplementary Fig. 6B,D,H,J, arrows). In contrast, mutant mice of the same age showed significantly reduced amounts of p-PKC $\zeta$ and p-GSK3 $\beta$ in this HF region (Fig. $4 \mathrm{D}^{\prime}, \mathrm{F}^{\prime}$, arrows; Supplementary Fig. $6 \mathrm{~B}^{\prime}, \mathrm{D}^{\prime}, \mathrm{H}^{\prime}, \mathrm{J}^{\prime}$, arrows).

In the epidermis of 3-, 9-, and 14-d-old control mice, PKC $\zeta$ and GSK3 $\beta$ were phosphorylated in basal and suprabasal regions (Fig. 4C,E; Supplementary Fig. 6A, C, G, II). In the absence of $\mathrm{Cdc} 42, \mathrm{pPKC} \zeta$ was strongly reduced in the whole epidermis (Fig. 4C'; Supplementary, Fig. $6 A^{\prime}, G^{\prime}$, arrows), while p-GSK3 $\beta$ was lost specifically in the basal keratinocytes (Fig. 4E', arrowheads; Supplementary Fig. $6 \mathrm{C}^{\prime}, \mathrm{I}^{\prime}$, arrowheads), but not in the suprabasal layers (Fig. 4E', arrows; Supplementary Fig. $6 \mathrm{C}^{\prime}, \mathrm{I}^{\prime}$, arrows). Western blot analysis confirmed the reduction of p-PKC $\zeta$ and p-GSK3 $\beta$ in the epidermis of 3-dold mutant mice (Fig. 4B). Also at later time points (2 wk, $3 \mathrm{mo}, 4.5 \mathrm{mo})$, p-GSK3 $\beta$ was decreased, while total cellular GSK3 $\beta$ was unchanged (quantification in Fig. 4A; representative blots in Supplementary Fig. 8A). 

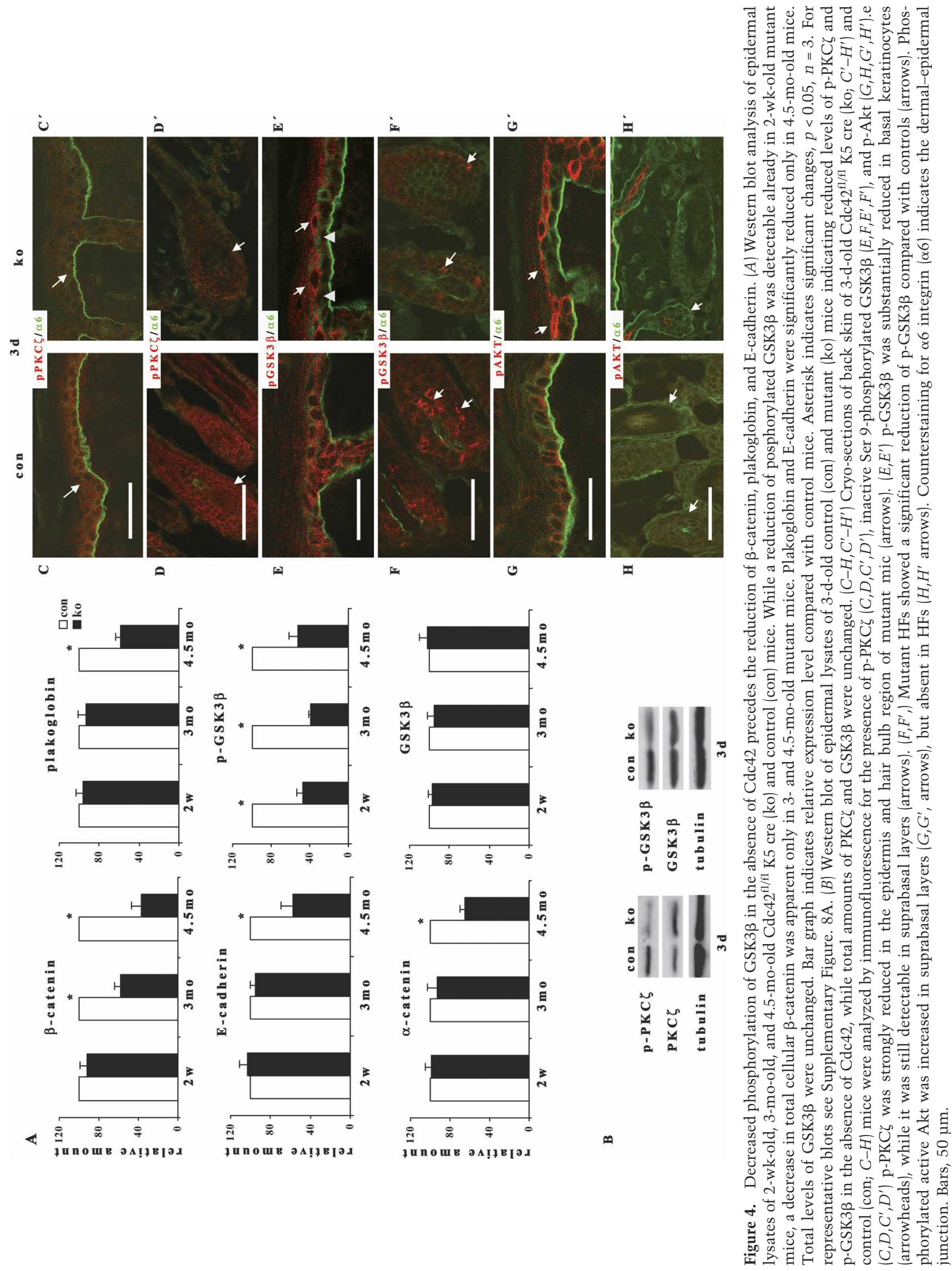
Wu et al.

GSK3 $\beta$ can be phosphorylated by Akt. To test whether increased Akt activity in suprabasal layers of Cdc42deficient mice could explain the phosphorylation of GSK3 $\beta$ restricted to the suprabasal layers, we stained skin sections of 3-, 9-, and 14-d-old mice for the presence of phosphorylated Akt (p-Akt) (Fig. 4G, G'; Supplementary Fig. $\left.6 \mathrm{E}, \mathrm{E}^{\prime}, \mathrm{K}, \mathrm{K}^{\prime}\right)$. Indeed, only suprabasal layers of mutant mice showed detectable amounts of active Akt, which might rescue the loss of Cdc42-dependent phosphorylation of GSK3 $\beta$ (Fig. 4G'; Supplementary Fig. $6 \mathrm{E}^{\prime}, \mathrm{K}^{\prime}$, arrows). Neither control nor mutant mice showed detectable levels of $\mathrm{p}$-Akt in the hair bulb region (Fig. 4H, $\mathrm{H}^{\prime}$, arrows; Supplementary Fig. 6F, $\mathrm{F}^{\prime}, \mathrm{L}, \mathrm{L}^{\prime}$, arrows).

Previously, keratin 6 was shown to increase Akt activity (Santos et al. 2002). Interestingly, keratin 6 was overexpressed in mutant mice only in the suprabasal layers (Supplementary Fig. 2F'), correlating well with the observed Akt activation.

These data suggest that loss of Cdc42 leads to a reduced activation of PKC $\zeta$ and a decreased phosphorylation of GSK3 $\beta$ at Ser 9 in HFs and basal keratinocytes in vivo.

\section{Cdc42 regulates $\beta$-catenin degradation in vivo}

We next investigated whether the Cdc42-dependent regulation of GSK3 $\beta$ phosphorylation involves a Par6PKC $\zeta$ complex as reported for astrocytes (EtienneManneville and Hall 2001, 2003). Immunoprecipitation of PKC $\zeta$ from epidermal lysates of control mice coprecipitated Par6 (Fig. 5A), showing that keratinocytes har- bor a cytosolic complex of Par6 and PKC $\zeta$. Furthermore, immunofluorescent staining detected Par3, Par6, and PKC $\zeta$ in the epidermis and HFs of control and mutant mice at 3, 9, and $14 \mathrm{~d}$ of age (Supplementary Fig. 7). However, $\mathrm{PKC} \zeta$ seemed to be reduced in the HFs at 9 and $14 \mathrm{~d}$ (Supplementary Fig. $7 \mathrm{H}, \mathrm{H}^{\prime}, \mathrm{N}, \mathrm{N}^{\prime}$ ).

In contrast to astrocytes, antibodies against $\mathrm{PKC} \zeta$ or Par6 also coprecipitated the 100-kDa isoform Par3 (Fig. 5A), which cannot directly interact with PKC $\zeta$. This suggests the presence of a Par6-Par3-PKC $\zeta$ complex in keratinocytes. This complex can form even in the absence of Cdc42, since Par6 coprecipitated with Par3 and PKC $\zeta$ also from epidermal lysates of Cdc42-deficient mice (Fig. $5 \mathrm{~A})$.

To increase the amount of Cdc42-GTP, we transduced spontaneously immortalized keratinocytes with a constitutively active mutated form of Cdc42 (Cdc42V12) (Supplementary Fig. 8C). In lysates from these cells, Par6 and $\mathrm{Cdc} 42$ coimmmunoprecipitated, indicating that GTP-bound Cdc42 is binding efficiently to Par6 (Fig. 5A). In epidermal lysates of normal mice, no detectable amounts of Cdc42 could be precipitated together with Par6, conceivably due to low endogenous levels of Cdc42-GTP (data not shown).

Finally, PKC $\zeta$ coprecipitated in epidermal lysates with GSK3 $\beta$ (Fig. 5A). This interaction, however, does not prove that PKC $\zeta$ is phosphorylating GSK3 $\beta$ in the $\beta$-catenin destruction complex, since many reports suggest that this GSK3 $\beta$ is insulated from other cellular pools of GSK3 $\beta$ (Doble and Woodgett 2003). Since attempts to directly assess the phosphorylation of GSK3 $\beta$ in the degradation complex failed, we indirectly mea-
Figure 5. Cdc42 binds to a Par6-Par3PKCל complex in keratinocytes and controls axin phosphorylation in vivo. $(A) \mathrm{Im}$ munoprecipitations (IP) of lysates from wild-type epidermis, Cdc42-null epidermis, or keratinocytes expressing constitutively active Cdc42 (Cdc42V12) were carried out as indicated. Antibodies against laminin 5 were used in control IPs (con). A dash indicates total cell lysate. Western blots (WB) were performed with the antibodies indicated at the left side. The first two series of IPs demonstrated the presence of a Par6Par3-PKC $\zeta$ complex in wild-type epidermis. Note that $\mathrm{PKC} \zeta$ precipitated together with the 100-kDa form of Par3, to which it can only bind indirectly. IPs from Cdc42V12-expressing keratinocytes showed that Cdc 42 associates with Par3 and PKC $\zeta$. IP from Cdc42-null epidermis revealed the presence of a Par6-Par3-PKC $\zeta$ complex also in the absence of Cdc42. Finally, GSK3 $\beta$ (arrow) precipitated together with $\mathrm{PKC} \zeta$ from lysates of wild-type epidermis. Western blot for IgG is shown as loading control. (B) Increased axin phophorylation in epidermal lysates of 3- and 14-d-old Cdc42-deficient mice. Phosphorylated and nonphosphorylated axin were distinguished by their different electrophoretic mobility. Two representative Western blots for axin are shown. Bar graph shows relative amounts $(n=4)$. Asterisk indicates significant changes $(p<0.05)$.
A
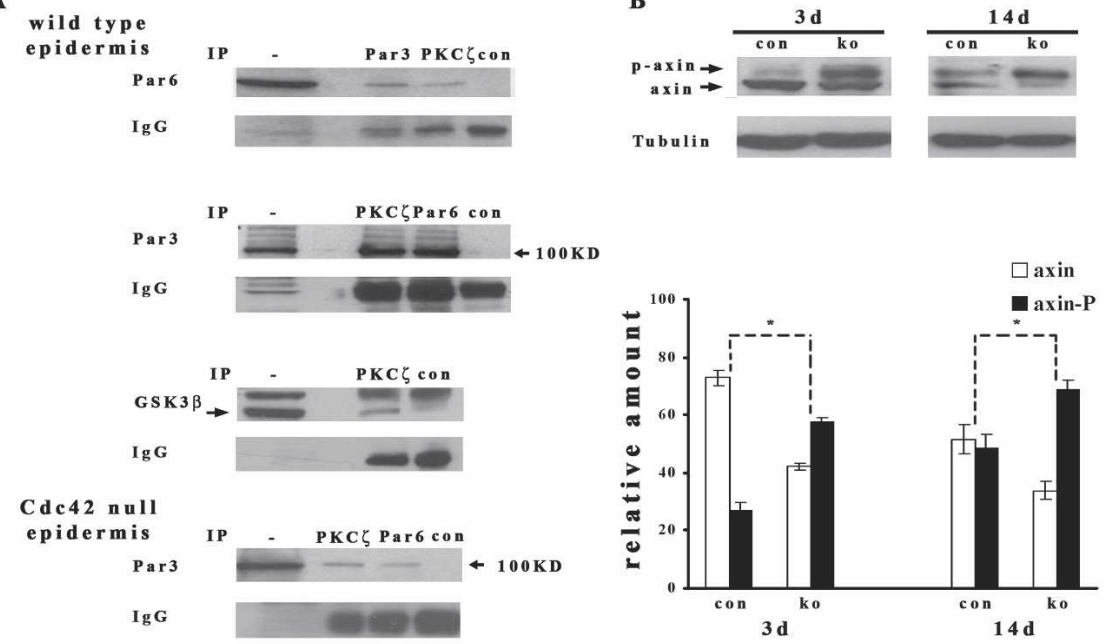

Cdc 42 V 12 keratinocytes Cdc 42 Ig G

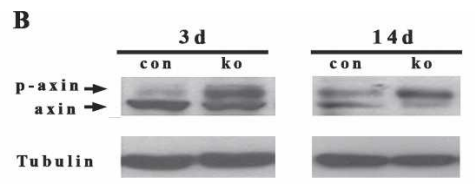

B (1)

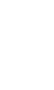


sured the kinase activity of GSK3 $\beta$ in the degradation complex by determining the phosphorylation of axin. Axin is present in the degradation complex and is known to be phosphorylated by GSK3 3 (Willert et al. 1999). Axin phosphorylation is also important for the degradation of $\beta$-catenin, because it is required for efficient binding of $\beta$-catenin to the complex (Willert et al. 1999). Since Ser 9 phosphorylation inhibits the kinase activity of GSK3 $\beta$, one expected an increased phosphorylation of axin in Cdc42-deficient keratinocytes, corresponding to a decreased phosphorylation of GSK3 $\beta$ at Ser 9.

Phosphorylated and the nonphosphorylated forms of axin were distinguished by their different electrophoretic mobility and detected by Western blotting (Willert et al. 1999). We found that loss of Cdc42 corresponded to an increased axin phosphorylation in epidermal lysates of 3- and 14-d-old mice (Fig. 5B, quantification and representative Western blot). While at $3 \mathrm{~d}$ the relative amount of p-axin in the epidermis was increased from $\sim 25 \%$ to $55 \%$ in the absence of Cdc 42 , it increased in 2 -wk-old mice from $\sim 50 \%$ to $70 \%$, suggesting increased GSK3 $\beta$ activity in the $\beta$-catenin degradation complex and increased axin-dependent binding of $\beta$-catenin to the degradation complex.

These experiments indicate that $\mathrm{Cdc} 42$ is regulating the kinase activity of GSK3 $\beta$ in the $\beta$-catenin-binding complex in vivo, most likely via Par6-Par3-PKC $\zeta$-mediated phosphorylation of GSK3 $\beta$ at Ser 9, which reduces GSK $3 \beta$ activity and thus stabilizes $\beta$-catenin.

\section{Cdc42 regulates $\beta$-catenin degradation}

cell autonomously

To assess whether the effect of Cdc 42 on the turnover of $\beta$-catenin is cell autonomous, we analyzed primary keratinocytes and spontaneously immortalized keratinocytes in vitro.

As expected, overexpression of constitutively active Cdc42 (Cdc42V12) in immortalized keratinocytes strongly increased the level of Cdc42-GTP and resulted in an increased phosphorylation of GSK3 $\beta$ and a stabilization of $\beta$-catenin (quantification in Fig. 6A; representative blots in Supplementary Fig. 8D).

In contrast to epidermal lysates of 4.5-mo-old mice, primary Cdc42-deficient keratinocytes established from these mice and grown for $5 \mathrm{~d}$ at low-calcium conditions unexpectedly showed similar levels of p-GSK3 $\beta$, total GSK3 $\beta, \beta$-catenin, plakoglobin, and E-cadherin as control cells (Supplementary Fig. 8A). Spontaneously immortalized keratinocytes lacking Cdc42 behaved identically (Fig. 6B).

Immunofluorescent analysis of skin sections of mutant mice had suggested a possible compensatory role of Akt in suprabasal keratinocytes in the absence of Cdc42 (Fig. 4G, $\mathrm{G}^{\prime}$; Supplementary Fig. $6 \mathrm{E}, \mathrm{E}^{\prime}, \mathrm{K}, \mathrm{K}^{\prime}$ ), whereby the enhanced Akt activation might be caused by increased expression of keratin 6 (Supplementary Fig. 2F, $F^{\prime}$ ). Comparing lysates from epidermis and primary keratinocytes from normal Cdc42-expressing mice, we found that cultured keratinocytes express higher levels of keratin 6 and have an increased phosphorylation of Akt compared with epidermis (Supplementary Fig. 8E). To test whether this increased activation of Akt could compensate for the loss of Cdc42 in vitro, we inhibited Akt activation in vitro.

Immortalized control and mutant keratinocytes were starved for at least $16 \mathrm{~h}$, pretreated for $45 \mathrm{~min}$ with the PI3K inhibitor wortmannin, and then stimulated with serum-containing low-calcium medium for $2 \mathrm{~h}$. In control keratinocytes, wortmannin treatment decreased phosphorylation of Akt by $90 \%$, phosphorylation of GSK $3 \beta$ by $25 \%$, and the amount of cytosolic $\beta$-catenin by $10 \%$ (quantification in Fig. $6 \mathrm{~B}$; representative blots in Supplementary Fig. 8F). In the absence of Cdc42, the inhibition of Akt was similar, but the decrease of GSK3 $\beta$ phosphorylation and cytosolic $\beta$-catenin were significantly stronger at $62 \%$ and $37 \%$, respectively (Fig. $6 B_{\text {; }}$ Supplementary Fig. 8F; $n=4 ; p<0.005$ ).

Although wortmannin is only an indirect and nonspecific inhibitor of Akt, these data are in line with our hypothesis that the increased activation of Akt in keratinocytes in vitro compensates for the loss of Cdc42 with respect to GSK3 $\beta$ phosphorylation and $\beta$-catenin turnover and indicate that the effects of Cdc42 on GSK3 $\beta$ phosphorylation and $\beta$-catenin degradation are cell autonomous.

\section{Cdc42-dependent control of $\beta$-catenin degradation

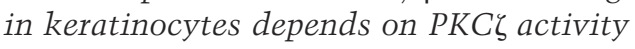

In astrocytes, Cdc42-induced phosphorylation of GSK3 $\beta$ and stabilization of $\beta$-catenin are mediated by PKC $\zeta$ (Etienne-Manneville and Hall 2003). To prove that the kinase activity of PKC $\zeta$ is required for the effect of $\mathrm{Cdc} 42$ on GSK3 $\beta$ phosphorylation and $\beta$-catenin degradation in keratinocytes, we inhibited $\mathrm{PKC} \zeta$ activity in vitro by Gö6983, which also inhibits other PKC isoforms (Gschwendt et al. 1996), and by PKC $\zeta$ pseudosubstrate (Standaert et al. 1997). Both PKC $\zeta$ inhibitors completely abrogated GSK3 $\beta$ phosphorylation and stabilization of cytosolic $\beta$-catenin induced by overexpression of constitutively active Cdc42 in keratinocytes (quantification in Fig. 6C; representative blots in Supplementary Fig. 8G). Furthermore, the difference in levels of p-GSK3 $\beta$ and cytosolic $\beta$-catenin between Cdc42-null and control keratinocytes in the presence of wortmannin was totally abrogated by both $\mathrm{PKC} \zeta$ inhibitors (quantification in Fig. $6 \mathrm{D}$; representative blots in Supplementary Fig. $8 \mathrm{H}$ ). These data strongly suggest that the Cdc42-mediated phosphorylation of GSK3 $\beta$ and stabilization of $\beta$-catenin are dependent on PKC $\zeta$.

The slight reduction of GSK3 $\beta$ phosphorylation and cytosolic $\beta$-catenin in Cdc42-null keratinocytes treated with Gö6983 or PKCל pseudosubstrate compared with untreated cells (Fig. 6D; Supplementary Fig. 8H) suggests that $\mathrm{PKC} \zeta$ is regulated also in a Cdc42-independent manner. Other pathways in addition to Cde 42 and Akt seem to control $\beta$-catenin degradation in keratinocytes via regulation of $\mathrm{PKC} \zeta$ activity.

These findings confirm the importance of $\mathrm{PKC} \zeta$ for the 
Wu et al.

Figure 6. $\operatorname{Cdc} 42$ regulates GSK3 3 phosphorylation and cytosolic $\beta$-catenin levels via $\mathrm{PKC} \zeta$, which can be compensated by Akt. (A) Expression of constitutively active Cdc42 (Cdc42V12) in immortalized keratinocytes resulted in significantly increased phosphorylation of GSK3 $\beta$ and increased amounts of cytosolic $\beta$-catenin, as shown in the bar graph $(n=4)$. For representative blots, see Supplementary Figure 8D. (B) Akt can compensate for the loss of Cdc42 with respect to GSK3 $\beta$ phosphorylation and $\beta$-catenin stabilization. Bar graphs from Western blot quantification show that GSK3 $\beta$ phosphorylation and $\beta$-catenin levels of Cdc42-null (ko) and control (wt) keratinocytes in vitro were similar in the absence of wortmannin, but significantly different in its presence $(n=4)$. For representative blots, see Supplementary Figure 8F. (C) Cdc42-dependent activation of GSK $3 \beta$ and stabilization of $\beta$-catenin are mediated by PKC $\zeta$. Keratinocytes expressing or not expressing constitutively active Cdc42 (Cdc42V12) were treated with the PKC $\zeta$ inhibitors Gö6983 or PKC $\zeta$ pseudosubstrate. Bar graphs from Western blot quantification show that inhibitor treatment completely abrogated the effect of Cdc42 $(n=4)$. For representative blots, see Supplementary Figure 8G. (D) Cdc42-dependent activation of GSK3 $\beta$ and stabilization of $\beta$-catenin in the presence of wortmannin are mediated by PKC $\zeta$. Cdc42-null (ko) or control (con) keratinocytes treated with wortmannin were incubated with the

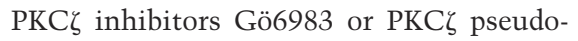
substrate. Bar graphs from Western blot quantification show that PKC $\zeta$ inhibitor treatment completely abrogated the effect of Cdc42 $(n=4)$. For representative blots, see Supplementary Figure $8 \mathrm{H}$. (E) Normal keratinocytes (wt), Cdc42-null keratinocytes (ko), and keratinocytes expressing constitutively active Cdc42 (Cdc42V12) were transiently transfected with TOPFLASH and FOPFLASH (negative control) luciferase reporter vectors for $\beta$-catenin-LEF/TCF-induced gene expression and Renilla luciferase vectors as transfection control and treated as indicated. Bar graphs show the ratio of TOPFLASH to FOPFLASH luciferase acivity normalized for transfection efficiency $(n \geq 3)$. Asterisk indicates significant changes $(p<0.05)$.

Cdc42-dependent control of $\beta$-catenin degradation in keratinocytes.

\section{Cdc42 is important for Wnt signaling in keratinocytes}

Assessing the expression of Wnt3, Wnt5a, and Wnt10b in the epidermis of 3-d-old mice by quantitative RT-PCR (qRT-PCR), we could not detect a significant change in expression of these Wnt genes (Supplementary Fig. 9C), which otherwise could have contributed to the phenotype.

Using the TOPFLASH/FOPFLASH system as a reporter to quantify the effect of Cdc42 on $\beta$-catenin-LEF/ TCF-mediated gene expression, we found that constitutive activation of Cdc42 (Cdc42V12) in keratinocytes results in a twofold activation of luciferase activity com-
B
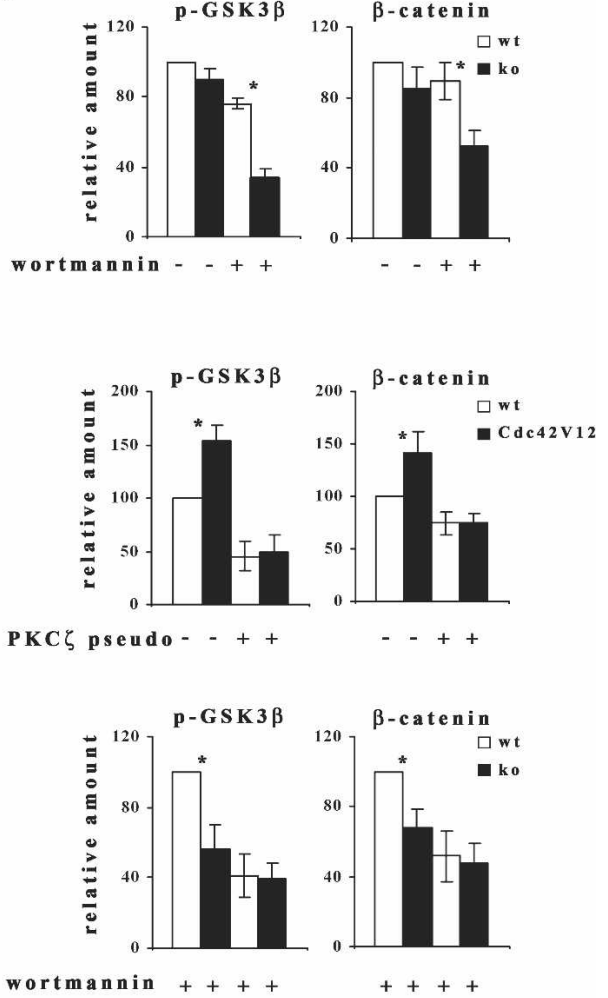

$\begin{array}{ll}\text { wortmannin }++++ & ++++ \\ \text { PKCלpseudo- }-++ & --++\end{array}$

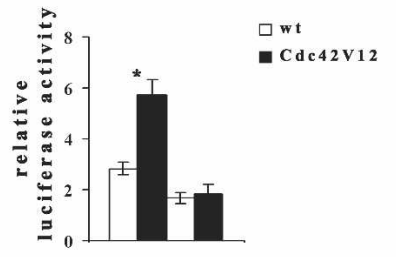

G $06983 \quad-++$ 
ratinocytes $(n=3)$. Similar stimulations were obtained in the presence of wortmannin (con: $2.12 \pm 0.38$; ko: $1.45 \pm 0.36 ; n=3$ ), suggesting that Cdc42 is important for effective Wnt signaling.

In keratinocytes expressing constitutively active Cdc42, the addition of Wnt3a led to a further $1.26 \pm 0.30$ fold increase of reporter activity. In the presence of the PKC $\zeta$ inhibitor Gö6983, not only was the reporter activity dependent on Cdc42V12 lost, but also the inducibility of reporter activity by Wnt3a, which was reduced to $1.03 \pm 0.07$-fold $(n=3)$-highlighting the importance of PKC $\zeta$ activity, largely regulated by $\mathrm{Cdc} 42$, for Wnt signaling in keratinocytes.

\section{Discussion}

Using mice with a keratinocyte-restricted deletion of the Cdc42 gene we demonstrated that Cdc42-dependent regulation of $\beta$-catenin and plakoglobin turnover is crucial for stem cell differentiation into the HF pathway and for normal cell-cell contacts between keratinocytes. These effects seem to be mediated at least in part by regulation of the activity of GSK3 $\beta$, which phosphorylates and targets $\beta$-catenin and plakoglobin for degradation (Fig. 7A,B).

\section{Progenitor cell differentiation in skin}

Epithelial skin stem cells are able to self-renew; to differentiate; and to form HFs, epidermis, and sebaceous

$\mathbf{A}$

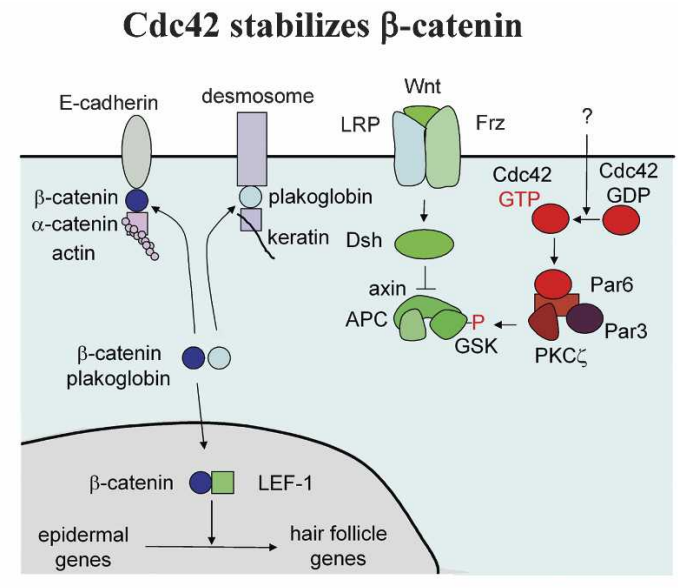

glands (Alonso and Fuchs 2003). $\beta$-catenin was shown to be crucial for the fate decision of skin stem cells by binding to members of the LEF/TCF transcription factor family and inducing the expression of HF-specific genes (Alonso and Fuchs 2003). If $\beta$-catenin is lost in keratinocytes early in development, no HFs form. If $\beta$-catenin is lost after HF formation has progressed or is completed, progenitor cells of the HFs differentiate within HF-derived cysts into epidermal keratinocytes, but not into HF keratinocytes (Huelsken et al. 2001). In the absence of Cdc42 in keratinocytes, severe defects became obvious that have certain similarities to those of mice with a late, keratinocyte-specific deletion of the $\beta$-catenin gene (Huelsken et al. 2001): First, the expression of HF-specific keratin genes was lost completely. Second, genes specific for interfollicular epidermal keratinocyte differentiation were expressed in former HF and HF-derived cysts. Interestingly, sebaceous glands were maintained in both mutants. These similarities suggest that $\mathrm{Cdc} 42$ and $\beta$-catenin control differentiation of skin progenitors via the same pathway. Indeed, HFs of 9-d-old Cdc42deficient mice show a loss of nuclear $\beta$-catenin.

In primary astrocytes, $\mathrm{Cdc} 42$ regulates $\beta$-catenin degradation by controlling the kinase activity of GSK3 $\beta$ (Etienne-Manneville and Hall 2003). GSK3 $\beta$ is part of a complex containing APC and axin, which binds and phosphorylates free, cytosolic $\beta$-catenin (Doble and Woodgett 2003). This targets $\beta$-catenin to proteasomal degradation, reducing cytosolic and nuclear concentra-
B

\section{Absence of Cde42 increases degradation of $\beta$-catenin and plakoglobin}

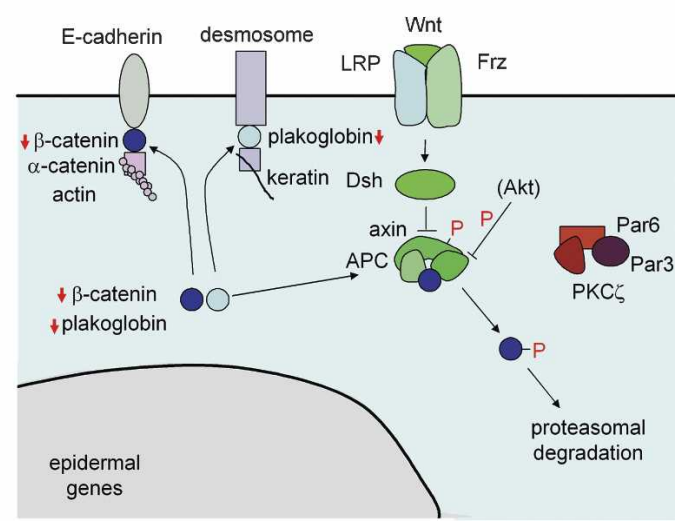

Figure 7. Cdc42 regulates HF differentiation and cell-cell contacts in keratinocytes by modulating the turnover of $\beta$-catenin and plakoglobin. Phosphorylation of free cytosolic $\beta$-catenin and plakoglobin by GSK3 $\beta$ targets these molecules for proteasomal degradation. GSK3 $\beta$ is part of a multiprotein complex that contains, among other molecules, APC and axin. Wnt signaling via the frizzled (Frz)-LPR receptor inhibits via disheveled (dsh) GSK3 $\beta$ activity, increasing the concentration of cytosolic $\beta$-catenin. (A) Activated Cdc42 can bind to a cytosolic complex of Par6-Par3-PKC $\zeta$, leading to inhibition of GSK3 $\beta$ activity by PKC $\zeta$-dependent phosphorylation of GSK3 $\beta$. This leads to reduced phosphorylation of axin and decreased phosphorylation and degradation of $\beta$-catenin. Free cytosolic $\beta$-catenin can then go to the nucleus and, together with a transcription factor of the LEF/TCF family (LEF-1), induce the expression of HF-specific genes. (B) Loss of Cdc42 results in a reduced phosphorylation and an increased activity of GSK3 $\beta$. This leads to an increased phosphorylation of axin, an increased degradation of free $\beta$-catenin and, consequently, decreased levels of nuclear $\beta$-catenin so that HF-specific genes cannot be induced. Instead, the default pathway of epidermal differentiation is used. Since plakoglobin is degraded by the same pathway as $\beta$-catenin, plakoglobin is also decreased in the absence of Cdc42, resulting in a reduction of junctional $\beta$-catenin and plakoglobin and, secondarily, a reduced transport of E-cadherin to the cell membrane. In suprabasal keratinocytes and in vitro, Akt activation compensates for the loss of Cdc42, leading to normal phosphorylation of GSK3 $\beta$ and normal levels of cytosolic $\beta$-catenin. 
tion of $\beta$-catenin and thus $\beta$-catenin-dependent gene expression. The primary target of GSK $3 \beta$ phosphorylation, however, is axin, since only phosphorylated axin allows efficient binding of $\beta$-catenin to the complex (Willert et al. 1999). Once $\beta$-catenin has bound, GSK3 $\beta$ also phosphorylates $\beta$-catenin. Axin phosphorylation can therefore be used as a measurement for GSK3 $\beta$ kinase activity within the $\beta$-catenin-binding complex (Willert et al. 1999). In the absence of Cdc42, axin phosphorylation in keratinocytes is increased, indicating enhanced GSK3 $\beta$ kinase activity and an enhanced capacity of the APCaxin-GSK $3 \beta$ complex to bind and phosphorylate $\beta$-catenin, targeting it for degradation (Fig. 7B). Cdc42, therefore, regulates $\beta$-catenin degradation in keratinocytes in vivo. This provides a mechanism for the observed effect of Cdc42 on the fate decision of epithelial skin progenitor cells. Interestingly, axin phosphorylation was not complete in the absence of Cdc42, suggesting that other pathways might be involved in the regulation of GSK3 $\beta$ activity in the $\beta$-catenin-binding complex.

One way to enhance GSK3 $\beta$ kinase activity is to reduce the phosphorylation of Ser 9 (Doble and Woodgett 2003). Although we were not able to determine directly the extent of the Ser 9 phosphorylation of GSK3 $\beta$ in the $\beta$-catenin-binding complex, the enhanced GSK3 $\beta$ kinase acitivity, measured by increased axin phosphorylation, correlated well with the reduced phosphorylation of total cellular GSK3 $\beta$ at Ser 9 in Cdc42-deficient keratinocytes. Our coimmunoprecipitation and inhibitor studies strongly suggest that, in normal keratinocytes, GTPbound Cdc42 binds to a preformed complex of Par6Par3-PKC $\zeta$ leading to PKC $\zeta$-mediated phosphorylation of GSK3 $\beta$ (Fig. 7A). This is different from astrocytes, where Par3 is reportedly not present in the complex (Etienne-Manneville and Hall 2001, 2003), but similar to other cell types where Par6-Par3-aPKC complexes have been described and are proposed to be regulated by $\mathrm{Cdc} 42$ (Joberty et al. 2000; Lin et al. 2000). GSK3 $\beta$ phosphorylation is not exclusively regulated by $\mathrm{Cdc} 42$, since Akt is also contributing to it, as our inhibitor studies revealed (at least in the absence of Cdc42). In basal-layer keratinocytes, however, where Akt activity is low, Cdc42 is the major regulator of GSK3 $\beta$ phosphorylation.

Wnt and BMP signaling control $\beta$-catenin-dependent gene expression by regulating $\beta$-catenin degradation (Fig. 7A; Alonso and Fuchs 2003; Kobielak et al. 2003). Since $\mathrm{Cdc} 42$ also regulates $\beta$-catenin turnover in keratinocytes, our data imply that Cdc42 is modulating Wnt and BMP signal transduction at the level of $\beta$-catenin.

Indeed, direct evaluation of $\beta$-catenin-LEF/TCF-mediated reporter gene activity in keratinocytes confirmed that Cdc42 activation results in increased reporter activity, that this effect seems to be dependent on PKC $\zeta$ activity, and that Cdc42 is important for Wnt3-induced reporter activity. Interestingly, our data hint that Cdc42 might also regulate reporter activity by a mechanism independent from $\beta$-catenin turnover, since Cdc42-null keratinocytes showed a significantly lower reporter activity than control cells, although levels of cytosolic $\beta$-catenin were only slightly reduced.
How Cdc42 activation in the HF is controlled remains an open question. Since many different pathways such as growth factor receptor, E-cadherin, or integrin signaling all regulate $\mathrm{Cdc} 42$ activation, $\mathrm{Cdc} 42$ could be an integration point for many different signaling cascades.

Recently, it was shown that Racl is crucial for the maintenance of skin stem cells in vivo (Benitah et al. 2005). Although Rac1 and Cdc42 share many effectors and Cdc42 is important for a significant part of Rac1 activation, at least in fibroblasts (Czuchra et al. 2005), the phenotypes of mice with a keratinocyte-restricted deletion of Rac1 of Cdc42 are very different, suggesting that Racl's and Cdc42's function in epidermis are rather distinct.

\section{Cell-cell contacts in the epidermis}

Cell-cell contacts between keratinocytes are mediated by adherens junctions and desmosomes (Perez-Moreno et al. 2003). Mice lacking Cdc42 restricted to keratinocytes show a surprisingly delayed impairment of epidermal cell-cell contacts, which corresponds to a severe reduction of the total cellular levels of E-cadherin, plakoglobin, and $\beta$-catenin. After $3 \mathrm{mo}$, total cellular $\beta$-catenin is significantly reduced, while decreases in the amounts of plakoglobin and E-cadherin are detectable only in 4.5-mo-old mutant animals. At first glance, this late response to the loss of Cdc42 protein would seem to conflict with the quick reduction of cytosolic $\beta$-catenin in Cdc42-null keratinocytes in vitro treated with PI3K inhibitor and also with the reduced levels of nuclear $\beta$-catenin in HF of 9-d-old mice.

However, our data indicate that loss of Cdc42 affects only the degradation of cytosolic $\beta$-catenin, which is a small part of the total cellular $\beta$-catenin. Reduction of cytoplasmic $\beta$-catenin leads to quick loss of nuclear $\beta$-catenin and in keratinocyte stem cells to impaired HF differentiation. In contrast, junctional $\beta$-catenin seems to be rather independent on cytosplasmic levels of $\beta$-catenin. Yet, the pools are not completely separated, since changes in E-cadherin expression can lead to changes in cytoplasmic $\beta$-catenin (Heasman et al. 1994; Cox et al. 1996; Fagotto et al. 1996; Sanson et al. 1996; Orsulic et al. 1999) and tyrosine phosphorylation of $\beta$-catenin seems to dissociate it from the adherens junctions (Piedra et al. 2003; Brembeck et al. 2004). Our data suggest that long-lasting reduction in cytoplasmic $\beta$-catenin indeed reduces junctional $\beta$-catenin (Fig. 7B). We speculate that the late reduction of total cellular $\beta$-catenin observed in Cdc42 mutant mice reflects a long half-life of $\beta$-catenin at the epidermal adherens junctions in vivo. Desmosomes are known to be even more stable than adherens junctions, and the cytoplasmic pools of plakoglobin are even smaller than those of $\beta$-catenin (Sadot et al. 1998, 2000; Simcha et al. 1998). This offers a reasonable explanation why total cellular plakoglobin, which is degraded by the same pathway as $\beta$-catenin (Fig. $7 \mathrm{~B})$, is significantly reduced much later than $\beta$-catenin. If both $\beta$-catenin and plakoglobin decline, E-cadherin is not transported any more to the cell surface /Chen et al. 
1999|. Therefore, the loss of E-cadherin is most plausibly secondary to the combined loss of $\beta$-catenin and plakoglobin.

Two other potential pathways by which Cdc42 could regulate E-cadherin-mediated cell-cell interaction can be ruled out as a cause for defective cell-cell contacts observed in Cdc42-deficient mice. Since IQGAP is removed from the cell-cell contacts and reduced in expression in the absence of $\mathrm{Cdc} 42$, while $\beta$-catenin is still present at the cell-cell junctions, impaired cell-cell contacts cannot be due to an increased binding of IQGAP to $\beta$-catenin, severing the connection of E-cadherin to the actin cytoskeleton (Kuroda et al. 1998; Fukata et al. 1999). Furthermore, loss of Cdc42 does not reduce the epidermal levels of p120, suggesting that p120 is also not involved in the reduction of E-cadherin in keratinocytes (Peifer and Yap 2003).

Although we did not observe obvious changes in immunofluorescent staining of junctional molecules in the epidermis of young mutant mice, we cannot exclude that Cdc42 affects the maintenance of cell-cell contacts in the epidermis independent from the suggested regulation of $\beta$-catenin and plakogobin degradation. Future work has to clarify the importance of such a potential pathway.

\section{Conclusion}

Cdc42 is known to regulate the organization of the actin cytoskeleton and cell polarity. Here we show that Cdc42 is crucial for the differentiation of skin progenitor cells in vivo, adding a new facet to the effects of Cdc42. Furthermore, we demonstrate that $\beta$-catenin turnover in keratinocytes is not only regulatable by Wnts and BMPs, as shown previously, but also by other signaling pathways that control Cdc42 activity. Although more studies will be necessary to assess this model in other tissues, our current results significantly advance the understanding of the complexity of Cdc42 function in vivo and its cross-talk with other pathways.

\section{Materials and methods}

\section{Generation of mutant mice}

The complete mouse Cdc42 cDNA was used to screen a PAC library. The targeting vector consisted of a $2.6-\mathrm{kb}$ left arm, a loxP site, an 0.5-kb genomic fragment with the ATG containing exon 2, a neo-tk cassette flanked by loxP sites, and a $6.2-\mathrm{kb}$ right arm. Homologous recombinants were identified by Southern blot, transiently transfected with a Cre expression plasmid (kindly provided by Dr. Werner Müller, University of Cologne, Germany), and selected in the presence of FIAU. Clones with a floxed exon 2 were identified and used for the generation of chimeras by blastocyst injection. Germline offspring containing the conditional allele were mated with each other and intercrossed with mice expressing the cre recombinase under the control of the keratin 5 promoter (kindly provided by Dr. Jose Jorcano, CIEMAT, Madrid, Spain) (Ramirez et al. 2004). The mice were kept in a barrier facility according to the German rules of animal welfare.
Histology, immunofluorescence, antibodies, and electon microscopy

Hematoxylin-eosin, immunofluorescence staining, and electron microscopy were performed as described previously (Brakebusch et al. 2000).

The following antibodies were used: axin (kindly provided by Dr. Roel Nusse, Stanford University, Stanford, CA); IQGAP1, plakoglobin, Par6, PKCל (all Santa Cruz); Cdc42, Rac1, $\beta$-catenin (all Transduction Laboratories); E-cadherin, ZO-1, occludin (all Zymed); $\beta$-catenin, $\alpha$-catenin (all Sigma); phosphoAkt (Ser 473), Akt, phospho-GSK3 $\beta$ (Ser 9), GSK-3 $\beta$, phosphop38, p38, p-PKC $\zeta$ (all Cell Signaling); $\beta 4$ integrin, $\alpha 6$ integrin, p120 (all Pharmingen); $\beta 1$ integrin (Chemicon); PKC $\zeta$ (Upstate); Ki67, keratin 10 (all DAKO); keratin 6, keratin 14, loricrin (all Babco); laminin-5 (laminin 22 chain; kindly provided by Dr. Takako Sasaki, Max-Planck-Institute of Biochemistry, Martinsried, Germany); versican (kindly provided by Dr. Dieter Zimmermann, University of Zürich, Zürich, Switzerland); LEF1 (kindly provided by Dr. Rudolf Grosschedl, Gene Center, München, Germany); K6irs1, K6irs2, K6irs3, K6hf, hHa4, hHa5, hHb2 (Langbein et al. 2003), Par3 (kindly provided by Dr. Zhengiun Chen, Chinese Academy of Science, Shanghai, China); Par6 (kindly provided by Dr. Pontus Aspenström, Ludwig Institute, Uppsala, Sweden).

Fluorescence-conjugated secondary antibodies were from Jackson Immunoresearch. Antibodies were diluted according to the recommendation of the manufacturer. F-actin was detected by FITC-conjugated phalloidin (Molecular Probes). BrdU incorporation and TUNEL stainings were carried out using commercial kits (all Roche Diagnostics).

Primary keratinocytes, keratinocyte lines, treatments, and luciferase reporter assays

For newborn mice, separation of epidermis was performed as described earlier (Calderai et al. 2000). For adult mice, epidermal separation was carried out according to Romero et al. (1999).

Primary $\mathrm{Cdc} 42^{\mathrm{fl} / \mathrm{fl}}$ keratinocytes were spontaneously immortalized (Romero et al. 1999) and cultured in low-calcium keratinocyte-defined medium (Invitrogen). These cells were retrovirally transduced with Cdc42(V12) and selected for coexpressed neomycin resistance. Cdc42-null keratinocytes were obtained by retroviral cotransduction of EGFP and cre. EGFPexpressing cells were sorted by FACS and tested for the absence of Cdc42.

For inhibitor treatment, keratinocytes were starved for at least $16 \mathrm{~h}$ with DMEM (low-calcium); treated for $45 \mathrm{~min}$ with $50 \mathrm{nM}$ wortmannin, $1 \mu \mathrm{M}$ Gö6983 or $5 \mu \mathrm{M}$ PKC $\zeta$ pseudosubstrate inhibitor (all Calbiochem); and then stimulated with keratinocyte medium containing 10\% FCS for $2 \mathrm{~h}$.

Luciferase reporter assay was performed as described by Jamora et al. (2003). Briefly, keratinocytes were seeded and transfected in six-well plates with either TOPFLASH or FOPFLASH reporter vector (both firefly luciferase) and-to determine transfection efficiency-pRL-TK (Renilla luciferase) using the polyfect transfection reagent (Qiagen). After $36 \mathrm{~h}$, cells were treated or not treated for 90 min with $50 \mathrm{nM}$ wortmanin, $1 \mu \mathrm{M}$ Gö6983, or treated for $5 \mathrm{~h}$ with Wnt3-containing cell supernatant control supernatant in the presence or absence of $1 \mu \mathrm{M}$ Gö6983. After lysis, firefly luciferase and Renilla luciferase activity were determined using the dual-luciferase reporter kit (Promega). Firefly luciferase activity was normalized to Renilla luciferase acitivity. Shown is the ratio of normalized TOPFLASH to FOPFLASH activity.

Wnt3a-containing cell supernatant was obtained from 293 cells transfected with a Wnt3a expression vector (Upstate). 


\section{Biochemical analysis}

Western and Northern blotting were performed according to standard protocols. Tubulin was used to normalize for different protein amounts. Coimmunoprecipitation was carried out as described (Etienne-Manneville and Hall 2001). Hypotonic extracts were prepared as reported earlier (Lustig et al. 2002). Pulldown assays for Cdc42 and Rac1 were performed as described (Zondag et al. 2000). qRT-PCR was performed in triplicate as described by Mfopou et al. (2005). Expression levels were normalized to GAPDH as an internal control. The following primers were used: wnt3: forward, 5'-AGCTGCCAAGAGTGTATT CG-3'; reverse, 5'-CGATCTAGATCCTGCTTCTC-3'; Wnt5a: forward, $5^{\prime}$-CTTGGTGGTCTCTAGGTATG- ${ }^{\prime}$; reverse, $5^{\prime}$-CC TGATACAAGTGGCAGAGT-3'; wnt10b: forward, 5' -CGCCA GGTGGTAACGGAAA-3'; reverse, 5'-AAGATGGCTCTGCT CAGCC-3'.

\section{Acknowledgment}

We thank Dr. Jürgen Behrens for many essential tools, excellent advice, and reading the manuscript; Dr. Jose Jorcano for the K5 cre mice; Drs. Roel Nusse, Pontus Aspenström, Zhengjun Chen, Dieter Zimmermann, Takako Sasaki, and Rudolf Grosschedl for providing antibodies; Dr. Erik Danen for help in establishing Rho GTPase pulldown assays; Dr. Werner Müller for the cre vector; Drs. SabineWerner, Fiona Watt, and Carsten Frank for help in the generation of primary and immortalized keratinocytes; Ursula Kuhn and Elke Heyder for expert technical help; Dr. A. Sonnenberg for comments on the manuscript; and Dr. Reinhard Fässler for critically reading the manuscript and generous support. This work was funded by the Max Planck Society and the German Research Council (DFG).

\section{References}

Alonso, L. and Fuchs, E. 2003. Stem cells in the skin: Waste not, Wnt not. Genes \& Dev. 17: 1189-1200.

Benitah, S.A., Frye, M., Glogauer, M., and Watt, F.M. 2005. Stem cell depletion through epidermal deletion of Rac1. Science 309: 933-935.

Bierkamp, C., Schwarz, H., Huber, O., and Kemler, R. 1999. Desmosomal localization of $\beta$-catenin in the skin of plakoglobin null-mutant mice. Development 126: 371-381.

Bishop, A.L. and Hall, A. 2000. Rho GTPases and their effector proteins. Biochem. J. 348: 241-255.

Brakebusch, C., Grose, R., Quondamatteo, F., Ramirez, A., Jorcano, J.L., Pirro, A., Svensson, M., Herken, R., Sasaki, T., Timpl, R., et al. 2000. Skin and HF integrity is crucially dependent on $\beta 1$ integrin expression on keratinocytes. EMBO J. 19: 3990-4003.

Brembeck, F.H., Schwarz-Romond, T., Bakkers, J., Wilhelm, S., Hammerschmidt, M., and Birchmeier, W. 2004. Essential role of BCL9-2 in the switch between $\beta$-catenin's adhesive and transcriptional functions. Genes \& Dev. 18: 2225-2230.

Calderai, R., Suter, M., Baumann, D., de Bruin, A., and Müller, E. 2000. Long-term culture of murine epidermal keratinocytes. J. Invest. Dermatol. 114: 1064-1065.

Chen, Y.T., Stewart, D.B., and Nelson, W.J. 1999. Coupling assembly of the E-cadherin/ $\beta$-catenin complex to efficient endoplasmic reticulum exit and basal-lateral membrane targeting of E-cadherin in polarized MDCK cells. J. Cell Biol. 144: 687-699.

Chen, F., Ma, L., Parrini, M.C., Mao, X., Lopez, M., Wu, C., Marks, P.W., Davidson, L., Kwiatkowski, D.J., Kirchhausen,
T., et al. 2000. Cdc42 is required for $\mathrm{PIP}_{2}$-induced actin polymerization and early development but not for cell viability. Curr. Biol. 10: 758-765.

Cox, R.T., Kirkpatrick, C., and Peifer, M. 1996. Armadillo is required for adherens junction assembly, cell polarity, and morphogenesis during Drosophila embryogenesis. J. Cell Biol. 134: 133-148.

Czuchra, A., Wu, X., Meyer, H., van Hengel, J., Schroeder, T., Geffers, R., Rottner, K., and Brakebusch, C. 2005. Cdc42 is not essential for filopodium formation, directed migration, cell polarization, and mitosis in fibroblastoid cells. Mol. Biol. Cell 16: 4473-4484.

DasGupta, R., Rhee, H., and Fuchs, E. 2002. A developmental conundrum: A stabilized form of $\beta$-catenin lacking the transcriptional activation domain triggers features of hair cell fate in epidermal cells and epidermal cell fate in HF cells. $J$. Cell Biol. 158: 331-344.

Ding, V.W., Chen, R.H., and McCormick, F. 2000. Differential regulation of glycogen synthase kinase $3 \beta$ by insulin and Wnt signaling. J. Biol. Chem. 275: 32475-32481.

Doble, B.W. and Woodgett, J.R. 2003. GSK-3: Tricks of the trade for a multi-tasking kinase. J. Cell Sci. 116: 1175-1186.

Etienne-Manneville, S. and Hall, A. 2001. Integrin-mediated activation of Cdc42 controls cell polarity in migrating astrocytes through PKCร. Cell 106: 489-498.

. 2002. Rho GTPases in cell biology. Nature 420: 629635.

- 2003. Cdc42 regulates GSK-3 $\beta$ and adenomatous polyposis coli to control cell polarity. Nature 421: 753-756.

Fagotto, F., Funayama, N., Gluck, U., and Gumbiner, B.M. 1996. Binding to cadherins antagonizes the signaling activity of $\beta$-catenin during axis formation in Xenopus. J. Cell Biol. 132: $1105-1114$

Fukata, M., Kuroda, S., Nakagawa, M., Kawajiri, A., Itoh, N., Shoji, I., Matsuura, Y., Yonehara, S., Fujisawa, H., Kikuchi, A., et al. 1999. Cdc42 and Rac1 regulate the interaction of IQGAP1 with $\beta$-catenin. J. Biol. Chem. 274: 26044-26050.

Gandarillas, A. 2000. Epidermal differentiation, apoptosis, and senescence: Common pathways? Exp. Gerontol. 35: 53-62.

Gschwendt, M., Dieterich, S., Rennecke, J., Kittstein, W., Mueller, H.J., and Johannes, F.J. 1996. Inhibition of protein kinase $\mathrm{C} \mu$ by various inhibitors. Differentiation from protein kinase c isoenzymes. FEBS Lett. 392: 77-80.

Heasman, J., Crawford, A., Goldston, K., Garner-Hamrick, P., Gumbiner, B., McCrea, P., Kintner, C., Noro, C.Y., and Wylie, C. 1994. Overexpression of cadherins and underexpression of $\beta$-catenin inhibit dorsal mesoderm induction in early Xenopus embryos. Cell 79: 791-803.

Huelsken, J., Vogel, R., Erdmann, B., Cotsarelis, G., and Birchmeier, W. 2001. $\beta$-Catenin controls HF morphogenesis and stem cell differentiation in the skin. Cell 105: 533-545.

Jamora, C., DasGupta, R., Kocieniewski, P., and Fuchs, E. 2003. Links between signal transduction and adhesion in epithelial bud development. Nature 422: 317-322.

Joberty, G., Petersen, C., Gao, L., and Macara, I.G. 2000. The cell-polarity protein Par6 links Par3 and atypical protein kinase C to Cdc42. Nat. Cell Biol. 2: 531-539.

Kishimoto, J., Burgeson, R.E., and Morgan, B.A. 2000. Wnt signaling maintains the hair-inducing activity of the dermal papilla. Genes \& Dev. 14: 1181-1185.

Kobielak, K., Pasolli, H.A., Alonso, L., Polak, L., and Fuchs, E. 2003. Defining BMP functions in the hair follicle by conditional ablation of BMP receptor IA. J. Cell Biol. 163: 609-623.

Kuroda, S., Fukata, M., Nakagawa, M., Fujii, K., Nakamura, T., Ookubo, T., Izawa, I., Nagase, T., Nomura, N., Tani, H., et al. 1998. Role of IQGAP1, a target of the small GTPases 
Cdc42 and Rac1, in regulation of E-cadherin-mediated cellcell adhesion. Science 281: 832-835.

Langbein, L., Rogers, M.A., Praetzel, S., Winter, H., and Schweizer, J. 2003. K6irs1, K6irs2, K6irs3, and K6irs4 represent the inner-root-sheath-specific type II epithelial keratins of the human HF. J. Invest. Dermatol. 120: 512-522.

Lin, D., Edwards, A.S., Fawcett, J.P., Mbamalu, G., Scott, J.D., and Pawson, T. 2000. A mammalian PAR-3-PAR-6 complex implicated in Cdc42/Racl and aPKC signalling and cell polarity. Nat. Cell Biol. 2: 540-547.

Lustig, B., Jerchow, B., Sachs, M., Weiler, S., Pietsch, T., Karsten, U., van de Wetering, M., Clevers, H., Schlag, P.M., Birchmeier, W., et al. 2002. Negative feedback loop of Wnt signaling through upregulation of conductin/axin2 in colorectal and liver tumors. Mol. Cell. Biol. 22: 1184-1189.

Mfopou, J.K., Willems, E., Leyns, L., and Bouwens, L. 2005. Expression of regulatory genes for pancreas development during murine embryonic stem cell differentiation. Int. J. Dev. Biol. 49: 915-922.

Niemann, C., Owens, D.M., Hülsken, J., Birchmeier, W., and Watt, F.M. 2002. Expression of DeltaNLef1 in mouse epidermis results in differentiation of HFs into squamous epidermal cysts and formation of skin tumours. Development 129: 95-109.

Orsulic, S., Huber, O., Aberle, H., Arnold, S., and Kemler, R. 1999. E-cadherin binding prevents $\beta$-catenin nuclear localization and $\beta$-catenin/LEF-1-mediated transactivation. $J$. Cell Sci. 112: 1237-1245.

Ossipova, O., Bardeesy, N., DePnho, R.A., and Green, J.B. 2003. LKB! (XEEK1) regulates Wnt signalling in vertebrate development. Nat. Cell Biol. 5: 889-894.

Peifer, M. and Yap, A.S. 2003. Traffic control: p120-catenin acts as a gatekeeper to control the fate of classical cadherins in mammalian cells. J. Cell Biol. 163: 437-440.

Perez-Moreno, M., Jamora, C., and Fuchs, E. 2003. Sticky business: Orchestrating cellular signals at adherens junctions. Cell 112: 535-548.

Piedra, J., Miravet, S., Castano, J., Palmer, H.G., Heisterkamp, N., Garcia de Herreros, A., and Dunach, M. 2003. p120 Catenin-associated Fer and Fyn tyrosine kinases regulate $\beta$-catenin Tyr-142 phosphorylation and $\beta$-catenin- $\alpha$-catenin Interaction. Mol. Cell. Biol. 23: 2287-2297.

Ramirez, A., Page, A., Gandarillas, A., Zanet, J., Pibre, S., Vidal, M., Tusell, L., Genesca, A., Whitaker, D.A., Melton, D.W., et al. 2004. A keratin K5Cre transgenic line appropriate for tissue-specific or generalized Cre-mediated recombination. Genesis 39: 52-57.

Romero, M.R., Carroll, J.M., and Watt, F.M. 1999. Analysis of cultured keratinocytes from a transgenic mouse model of psoriasis: Effects of suprabasal integrin expression on keratinocyte adhesion, proliferation and terminal differentiation. Exp. Dermatol. 8: 53-67.

Sadot, E., Simcha, I., Shtutman, M., Ben-Ze'ev, A., and Geiger, B. 1998. Inhibition of $\beta$-catenin-mediated transactivation by cadherin derivatives. Proc. Nat. Acad. Sci. 95: 15339-15344.

Sadot, E., Simcha, I., Iwai, K., Ciechanover, A., Geiger, B., and Ben-Ze'ev, A. 2000. Differential interaction of plakoglobin and $\beta$-catenin with the ubiquitin-proteasome system. Oncogene 19: 1992-2001.

Sanson, B., White, P., and Vincent, J.P. 1996. Uncoupling cadherin-based adhesion from wingless signalling in Drosophila. Nature 383: 627-630.

Santos, M., Paramio, J.M., Bravo, A., Ramirez, A., and Jorcano, J.L. 2002. The expression of keratin $\mathrm{k} 10$ in the basal layer of the epidermis inhibits cell proliferation and prevents skin tumorigenesis. J. Biol. Chem. 277: 19122-19130.
Schmidt-Ullrich, R. and Paus, R. 2005. Molecular principles of hair follicle induction and morphogenesis. Bioessays 27: 247-261.

Simcha, I., Shtutman, M., Salomon, D., Zhurinsky, J., Sadot, E., Geiger, B., and Ben-Ze'ev, A. 1998. Differential nuclear translocation and transactivation potential of $\beta$-catenin and plakoglobin. J. Cell Biol. 141: 1433-1448.

Standaert, M.L., Galloway, L., Karnam, P., Bandyopadhyay, G., Moscat, J., and Farese, R.V. 1997. Protein kinase C- $\zeta$ as a downstream effector of phosphatidylinositol 3-kinase during insulin stimulation in rat adipocytes. Potential role in glucose transport. J. Biol. Chem. 272: 30075-30082.

Thoreson, M.A., Anastasiadis, P.Z., Daniel, J.M., Ireton, R.C., Wheelock, M.J., Johnson, K.R., Hummingbird, D.K., and Reynolds, A.B. 2000. Selective uncoupling of p120(ctn) from E-cadherin disrupts strong adhesion. J. Cell Biol. 148: 189202.

Tinkle, C.L., Lechler, T., Pasolli, H.A., and Fuchs, E. 2004. Conditional targeting of E-cadherin in skin: Insights into hyperproliferative and degenerative responses. Proc. Nat. Acad. Sci. 101: 552-557.

Vasioukhin, V., Bauer, C., Degenstein, L., Wise, B., and Fuchs, E. 2001. Hyperproliferation and defects in epithelial polarity upon conditional ablation of $\alpha$-catenin in skin. Cell 104: 605-617.

Willert, K., Shibamoto, S., and Nusse, R. 1999. Wnt-induced dephosphorylation of axin releases $\beta$-catenin from the axin complex. Genes \& Dev. 13: 1768-1773.

Young, P., Boussadia, O., Halfter, H., Grose, R., Berger, P., Leone, D.P., Robenek, H., Charnay, P., Kemler, R., and Suter, U. 2003. E-cadherin controls adherens junctions in the epidermis and the renewal of hair follicles. EMBO J. 22: 5723 5733.

Yuan, H., Mao, J., Li, L., and Wu, D. 1999. Supression of glycogen synthase kinase activity is not sufficient for leukemia enhancer factor-1 activation. J. Biol. Chem. 274: 3041930423.

Zondag, G.C., Evers, E.E., ten Klooster, J.P., Janssen, L., van der Kammen, R.A., and Collard, J.G. 2000. Oncogenic Ras downregulates Rac activity, which leads to increased Rho activity and epithelial-mesenchymal transition. I. Cell Biol. 149: 775-778. 


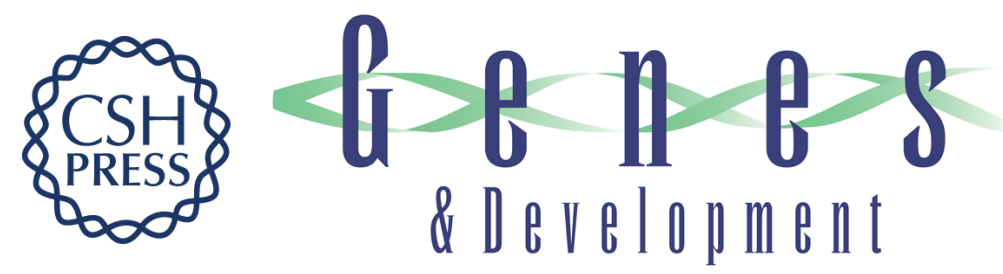

\section{Cdc42 controls progenitor cell differentiation and $\beta$-catenin turnover in skin}

Xunwei Wu, Fabio Quondamatteo, Tine Lefever, et al.

Genes Dev. 2006, 20:

Access the most recent version at doi:10.1101/gad.361406

\section{Supplemental http://genesdev.cshlp.org/content/suppl/2006/03/01/20.5.571.DC1 Material}

References This article cites 54 articles, 32 of which can be accessed free at: http://genesdev.cshlp.org/content/20/5/571.full.html\#ref-list-1

\section{License}

Email Alerting

Receive free email alerts when new articles cite this article - sign up in the box at the top Service 